\title{
The Effect of Progressive Muscle Relaxation and Hearing Holy Quran Sound on The Quality of Life Among Elderly with Hypertension
}

\author{
Dewi Kurniawati * \\ Nursing Department, Yarsi Health \\ Science College, Sumatera Barat, Indonesia
}

\author{
Pera Putra Bungsu \\ Nursing Department, Yarsi Health \\ Science College, Sumatera Barat, Indonesia
}

\begin{abstract}
Older population is significantly grown up in global society, and most of the elderly suffering with hypertension. Hypertension is one of the extremely disease which cause cardiovascular and decreasing the quality of life. Using complementary methods seems necessary to lessen the patients problem like using progressive muscle relaxation and hearing Holy Quran sound to elderly with hypertension. To assess the effectiveness of progressive muscles relaxation and hearing Holy Quran sound to the QOL in elderly with hypertension. On elderly with hypertension who is residing in Guguk Panjang area. We used quasy experimental study design which consisted of 38 participants and divided into two groups, 15 as intervention group and 23 participants as control group. In experiment group subject were practiced the progressive muscle relaxation and listened to the Holy Quran for 6 consecutive days. They have listened the last of three surah from the Holy Quran. The quality of life was measure using WHO-QOL BREF. Based on Mann Whitney test results the quality of life score shows significant difference in mean scores for total scores in qol before and after intervention between two groups $(p=0.004)$. Furthermore almost all domain also show significant difference. There is a significant difference between QoL experiments and control group after getting the progressive muscle relaxation and hearing the Quran sound among elderly with hypertension. These findings indicate that hearing the Quran sound will increase the quality of life of elderly with hypertension.
\end{abstract}

Keywords: Elderly, quality of life, progressive muscle relaxation, hypertension

Received: 30 October 2020; Accepted: 05 January 2021; Published: 24 March 2021

\section{INTRODUCTION}

Recently, the population of elderly significantly grow up in global society. Data in 2014, showed the number of older people more than 65 age years old was above 46 million, which representing $15 \%$ of the total U.S. population; and estimated will increase to $21 \%$ by 2030 [1, 2, 3, 4].

By aging-related the elderly will experience functional deteriorations and chronic illnesses such as hypertension [5]. Hypertension is more prevalent among older adults. The prevalence amongst those 45 to 54 years of age was $34.7 \%$; 65 to 74 years of age $64.7 \%$; and $77.3 \%$ in older adults $\geq 75$ years of age [6].

Hypertension is identified to have significant effects on kidney disease [7, 8]; cardiovascular disease such as heart failure, myocardial infarction, and stroke [9]; and a leading risk factor formortality [7]. About 7.1 million people are consequence to die because of hypertension in worldwide every year [5].

In Indonesia, hypertension becomes the five common degenerative diseases. Data in 2018 indicated an increasing number to $34.1 \%$ from $26.5 \%$ in 2013 [10]. The chronic disease have impact in Wuality of Life (QOL) of elderly patients. Currently some show that hypertension contributes to decrease the QOL of patients [11, 12]. The QOL of patient with hypertension is caused by issues which concern to pharmacological treatment [13].

\footnotetext{
${ }^{*}$ Correspondence concerning this article should be addressed to Dewi Kurniawati, Nursing Department, Yarsi Health Science College, Sumatera Barat, Indonesia. E-mail: data.peraputrabungsu@gmail.com

(C) 2021 The Author(s). Published by KKG Publications. This is an Open Access article distributed under a Creative Commons AttributionNonCommercial-NoDerivatives 4.0 International License.
} 
The data indicated that the effectiveness of antihypertensive therapy only by about $15 \%-20 \%$, and it is still considering low to control of blood pressure [14, 15]. Only $10 \%$ of patients who report to have advantageous in lowering blood pressure after taking the medication [16].

Therefore, using complementary methods to reduce patients' problems seems necessary. One of the basic and low-risk interventions, which can be used parallel to the treatment for these patients, is complementary or alternative medicine [17, 18].

The complementary medicine methods is using behavioral intervention such as progressive muscle relaxation [19] and hearing Holy Quran can increase the Quality of Life [20]. Progressive muscle relaxation is a physical stimulation and mental peace with emphasis on muscle systematic stretching and release (contraction-release) [19].

Study from Shahriari [19] revealed that mean scores of functional and overall domains of QoL had a significant difference practice progressive muscles relaxation compared to control. It shows the positive effect on improvement of QoL in the older adults. Besides that, current study found that hearing to the Quran voice will increase the QoL in elderly more over to the mental health domains followed by the life satisfaction domains [21].

The objective of the study was to assess the effectiveness of progressive muscles relaxation and hearing Holy Quran sound to the QOL in elderly with hypertension.

\section{METHODOLOGY}

This study conducted on elderly with hypertension who is residing in GugukPanjang area. We used quasy experimental study design which consisted of 38 participants and divided into two groups, 15 as intervention group and 23 participants as control group.

The inclusion criteria were: the participants sign the consent form and the aged more than 60 years old. For exclusion criteria included: the elderly with muscle and cardiovascular disease.

Data were collected in two section questionnaire. First was demographic characteristics, and second was quality of life. Quality of Life was measure using WHOQOL BREF which consists of 26 questions. The va- lidity and reliability of these questionnaires was established in some studies in Indonesia for Indonesian version [22, 23, 24]. The score of questionnaire using 5 point Likert scale that rates from 5 (strongly agree) to 1 (strongly disagree) and consists of 4 domains which are physical psychological, social and environmental dimension.

All respondent filled the consent form about their agreement to this study. Then quality of life was measure to experiment and control group before applying the intervention.In experiment group subject were practiced the progressive muscle relaxation and listened to the Holy Quran for 6 consecutive days. They have listened the last of three Surah from the Holy Quran.

In the current study progressive muscle relaxation defined to contraction and relaxation some muscle in some organ of the body which covered upper and lower hand, upper and lower leg, chest, abdomen and shoulder. The movement was shown by the trainer and also using screen sharing and participant were asked to follow the movement. Step one subject were asked to take the comfort position an then take in deep breathing for three times. After that they try to focus and concentration to follow the movement which start from the lower hand and last to upper leg. Muscle relaxation were practiced three times a week and repeated for two weeks. When the subjects finish to practice progressive muscle relaxation then they listened to the Holy Quran. After 2 weeks QoL questionnaire was filled in experimental group. In the control group QoL were completed in the first day and last day of the study.

Demographic data and QoL domain was describe by using frequency counts, means and standard deviation. The different between two groups was analysing by Mann Whitney test.

\section{RESULTS}

Table 1 shows demographic characteristic for experiment and control groups, which in the experimental group mean age $M=70.33 ; S D=7.128$, BMI $(M=24.78 ; S D=$ 3.545). For the control group the mean of age was $M=$ 69.13; $S D=7.097$, BMI $M=24.64 ; S D=2.954$. Most of respondent in both group have high consumption of natrium and less for physical activity. 
TABLE 1

DEMOGRAPHIC CHARACTERISTIC

\begin{tabular}{|c|c|c|c|c|}
\hline Characteristics & Int Group $(n=15)$ & $\%$ & Cont $\operatorname{Group}(n=23)$ & $\%$ \\
\hline Age & $70.33 \pm 7.128$ & & $69.13 \pm 7.097$ & \\
\hline BMI & $24.78 \pm 3.545$ & & $24.64 \pm 2.954$ & \\
\hline \multicolumn{5}{|l|}{ Gender } \\
\hline Man & 2 & 13.3 & 8 & 34.8 \\
\hline Woman & 13 & 86.7 & 15 & 65.2 \\
\hline \multicolumn{5}{|l|}{ Education } \\
\hline Basic school & 5 & 33.3 & 6 & 26.1 \\
\hline Middle school & 3 & 20 & 4 & 17.4 \\
\hline High school & 3 & 20 & 10 & 43.5 \\
\hline University & 4 & 26.7 & 3 & 13 \\
\hline \multicolumn{5}{|l|}{ Status } \\
\hline Widow & 9 & 60 & 7 & 30.4 \\
\hline \multicolumn{5}{|l|}{ Smoking } \\
\hline Yes & 0 & 0 & 2 & 8.7 \\
\hline No & 15 & 100 & 21 & 91.3 \\
\hline \multicolumn{5}{|c|}{ Natrium consumption } \\
\hline Yes & 12 & 80 & 20 & 87 \\
\hline No & 3 & 20 & 3 & 13 \\
\hline \multicolumn{5}{|c|}{ Family with Hypertension } \\
\hline Yes & 5 & 33.3 & 9 & 39.1 \\
\hline No & 10 & 66.7 & 14 & 60.9 \\
\hline \multicolumn{5}{|l|}{ Physical activity } \\
\hline Yes & 11 & 73 & 13 & 56.5 \\
\hline No & 4 & 27 & 10 & 43.5 \\
\hline
\end{tabular}

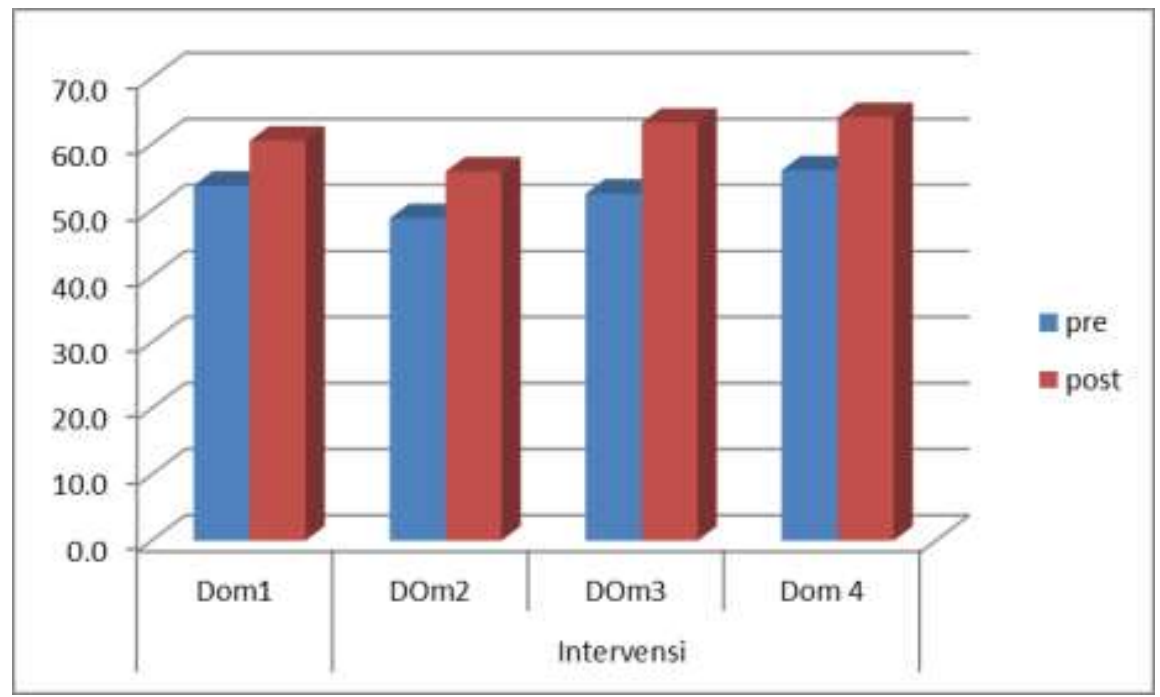

Fig. 1. Qol before and after in the experiment group 


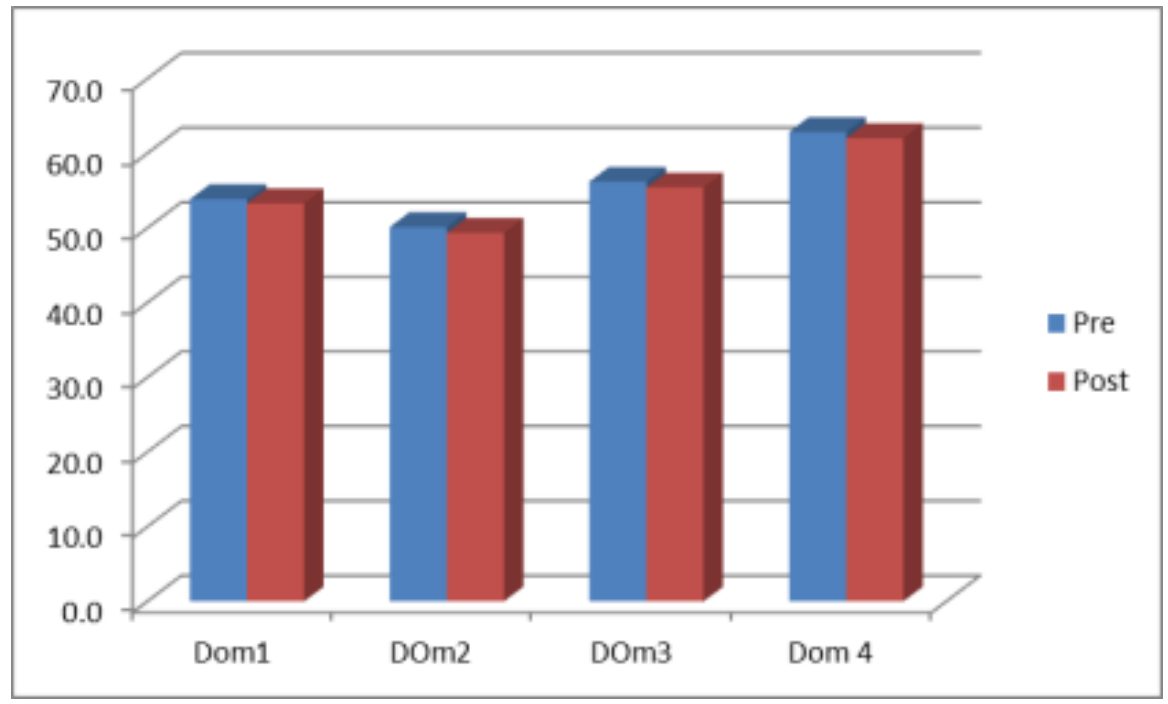

Fig. 2. Qol before and after in the control group

Fig. 1 shows the increasing of quality of life for all domains and for total QoL in the experiment group. And in Fig. 2 is for control group which display only slight difference between two groups.

Based on Mann Whitney test results the quality of life score shows significant difference in mean scores for total scores in qol before and after intervention between two groups ( $p=0.004$ ). Furthermore almost all domain also show significant difference except for environmental (Table 2).

TABLE 2

DIFFERENCE WITHIN AND BETWEEN TWO GROUP

\begin{tabular}{|c|c|c|c|c|c|c|}
\hline & & & Mean & $S D$ & $p$ Wilcoxon & $p$ Mann Whitney \\
\hline \multirow[t]{4}{*}{ Domain 1} & Intervention & Pre & 53.73 & \pm 6.912 & .014 & .013 \\
\hline & & Post & 60.53 & \pm 7.11 & & \\
\hline & Control & Pre & 53.87 & \pm 9.221 & .257 & \\
\hline & & Post & 53.3 & \pm 8.849 & & \\
\hline \multirow{4}{*}{ Domain 2} & Intervention & Pre & 48.8 & \pm 5.647 & .002 & .02 \\
\hline & & Post & 55.87 & \pm 6.567 & & \\
\hline & Control & Pre & 50.13 & \pm 8.019 & .083 & \\
\hline & & Post & 49.35 & \pm 7.643 & & \\
\hline \multirow[t]{4}{*}{ Domain 3} & Intervention & Pre & 52.53 & \pm 11.759 & .032 & .048 \\
\hline & & Post & 62.87 & \pm 10.501 & & \\
\hline & Control & Pre & 56.22 & \pm 12.284 & .083 & \\
\hline & & Post & 55.43 & \pm 12.471 & & \\
\hline \multirow[t]{4}{*}{ Domain 4} & Intervention & Pre & 56.07 & \pm 9.051 & .005 & .906 \\
\hline & & Post & 64.13 & \pm 3.523 & & \\
\hline & Control & Pre & 62.87 & \pm 9.392 & .102 & \\
\hline & & Post & 62.04 & \pm 9.108 & & \\
\hline
\end{tabular}

\section{DISCUSSION}

The results showed that mean scores of physical health, psychological and social relationship had a significant difference after 2 weeks intervention in study group, compare to control group. It indicated positive conse- quences when doing progressive muscle relaxation and hearing Holy Quran sound on increasing the QoL among elderly with hypertension. [25] found that the quality of life was increase in different domain after practicing progressive muscles relaxation. Another studies have 
consistent result with this study, QoLimprovement was occurred after practicing progressive muscles relaxation in patients with prostate and breast cancer, multiple sclerosis and post traumatic syndrome [19, 26, 27, 28]. Study from [29] indicated significant relationship between progressive muscle relaxation and dance therapy on quality of life in elderly.

[30] stated that progressive muscle relaxation relieves tension in the muscles so that the muscles relax. Progressive muscle relaxation will cause the body to concentrate on muscle tension in several organs of the body. By releasing and decreasing muscle tension, this will increase a sense of comfort and peace for the body [17].

In this study we found most of respondent report decreasing the pain in the body after practicing progressive muscles relaxation in experiment group. Other studies are consistent with the current study and confirm pain relief through this approach. A systematic review examined the effect of muscle relaxation on breast cancer. Seven articles found this approach to provide pain and pain relief in breast cancer patients [31]. In a study comparing two nonpharmacological approaches, PMR and music therapy, for pain in cancer patients, the effect of muscle relaxation was significantly higher than that of music therapy. It could be argued that this non-pharmacological approach caused pain relief and ultimately improvement in quality of life in cancer patients [23].Similar findings also indicated from [32] patients with hypertension claim that regular relaxation training can reduce physical disorders related to hypertension. Some of the physical complaints that subside due to relaxation are neck pain, headaches, difficulty sleeping, body stiffness and aches. Psychologically, relaxation training makes people with hypertension feel relaxed, which in turn reduces the feeling of discomfort and makes them calm, feeling anxious and worried less.

In a relaxed condition, the body through the brain will produce endorphrin which functions as the body's natural analgesic and can relieve pain (physical complaints). Likewise with psychological conditions, by doing guide imagery and hypnosis there will be a release of negative emotions such as feelings of anger, anxiety, etc. which are implications of improving the quality of life from a psychological side [32].

Besides that, hearing Holy Quran sound also promote quality of life. [21] stated that after hearing Holy Quran sound in intervention group the QoL was higher than before intervention. This result also similar to [33] that QoL will enhance individual mental health.

The Qur'an is well-known as the mind and soul therapist and sometimes it is acknowledged as the resource of curing treatment [34]. Since human nature has a tendency to listen the rhythm and enjoyment of order, the Holy Quran has a powerful expression and an enchanting style that affects individuals. The Quran is full of passages dealing with relaxation and how to achieve it, and provides a number of strategies for dealing with stressful situations. In general, the Quran calls for peaceful and serenity [21]

Therefore, it is important to manage the level of psychological aspects between individuals, as listening to the Quran is linked to the quality of life, it stimulates the alpha brain wave, changes negative emotions and creates a sense of relaxation, causing the release of endorphins are promoted [35]. The Quran also provided many solutions, principles, andguidelines for mental health $[33,36]$.

\section{CONCLUSION}

The findings of the present study showed that combination of progressive muscle relaxation and hearing the Quran sound will positively affected the quality of life in elderly such us physical pain relief and relaxation in elderly. In addition after the intervention almost elderly reported feel healthier and decrease sleep disturbances at night. Regarding the findings of the present study we can conclude that the quality of life will promoted after the intervention. Therefore, implementing such interventions is recommended to promote health in elderly, especially with hypertension.

\section{A. Limitation and Future Research}

The study has limitation since we did this research during pandemic, it is hard to find our respondent. In the future research we suggest to increase the number of respondent.

\section{B. Ethical Consideration \& Compliance with Ethical Guideline}

After getting letter permission from department of national and political unity, the researcher finished the study questionnaires. Before filling the questionnaires, all participants signed the consent form and also get some explanation about this study.

\section{Funding}

This study received the grant from The Ministry of Research, Technology, \& Higher Education of Indonesia.

\section{REFERENCES}

[1] Centers for Disease Control, "Faststats: Older persons' health," Centers for Disease Control, Tech. Rep., 2015. [Online]. Available: 
https://bit.ly/3jyrWLG

[2] Federal Interavency Forum on Aging-Related statistics, "Older Americans - Key indicators of well-being," Federal Interagency Forum on AgingRelated Statistics, Tech. Rep., 2016. [Online]. Available: https://bit.ly/3w4B2CN

[3] J. M. Ortman, V. A. Velkoff, and H. Hogan, "An aging nation: The older population in the United States," US Department of Commerce, Economics and Statistics Administration, US, Tech. Rep., 2014. [Online]. Available: https://bit.ly/2Tti7Ed

[4] M.-L. Chen, J. Hu, T. P. McCoy, S. Letvak, and L. Ivanov, "Effect of a lifestyle-based intervention on health-related quality of life in older adults with hypertension," Journal of Aging Research, vol. 2018, pp. 1-8, 2018. doi: https://doi.org/10.1155/ 2018/6059560

[5] P. Son, N. Quang, N. Viet, P. Khai, S. Wall, L. Weinehall, R. Bonita, and P. Byass, "Prevalence, awareness, treatment and control of hypertension in Vietnam-results from a national survey," Journal of Human Hypertension, vol. 26, no. 4, pp. 268-280, 2012.

[6] E. J. Benjamin, M. J. Blaha, S. E. Chiuve, M. Cushman, S. R. Das, R. Deo, S. D. De Ferranti, J. Floyd, M. Fornage, and C. Gillespie, "Heart disease and stroke statistics-2017 update: A report from the American heart association," Circulation, vol. 135, no. 10, pp. e146-e603, 2017. doi: https://doi.org/10. 1161/CIR.0000000000000485

[7] P. M. Kearney, M. Whelton, K. Reynolds, P. Muntner, P. K. Whelton, and J. He, "Global burden of hypertension: Analysis of worldwide data," The Lancet, vol. 365, no. 9455, pp. 217-223, 2005. doi: https://doi.org/10.1016/s0140-6736(05)17741-1

[8] N. T. Ha, H. T. Duy, N. H. Le, V. Khanal, and R. Moorin, "Quality of life among people living with hypertension in a rural Vietnam community," BMC Public Health, vol. 14, no. 1, pp. 1-9, 2014. doi: https://doi.org/10.1186/1471-2458-14-833

[9] C. M. Lawes, S. Vander Hoorn, and A. Rodgers, "Global burden of blood-pressure-related disease, 2001," The Lancet, vol. 371, no. 9623, pp. 1513-1518, 2008. doi: https://doi.org/10.1016/ S0140-6736(08)60655-8

[10] Health Research and Development Agency, $\mathrm{Na}$ tional report on basic health research results. Jakarta, Indonesia: Health Research and Development Agency, 2018.

[11] B. Uchmanowicz, A. Chudiak, and G. Mazur, "The influence of quality of life on the level of adher- ence to therapeutic recommendations among elderly hypertensive patients," Patient Preference and Adherence, vol. 12, p. 2593-2603, 2018. doi: https://doi.org/10.2147/PPA.S182172

[12] D. J. Trevisol, L. B. Moreira, A. Kerkhoff, S. C. Fuchs, and F. D. Fuchs, "Health-related quality of life and hypertension: a systematic review and metaanalysis of observational studies," Journal of $\mathrm{Hy}$ pertension, vol. 29, no. 2, pp. 179-188, 2011. doi: https://doi.org/10.1097/HJH.0b013e328340d76f

[13] Y. R. Chin, I. S. Lee, and H. Y. Lee, "Effects of hypertension, diabetes, and/or cardiovascular disease on health-related quality of life in elderly Korean individuals: A population-based cross-sectional survey," Asian Nursing Research, vol. 8, no. 4, pp. 267-273, 2014. doi: https://doi.org/10.1016/j.anr. 2014.10.002

[14] J. R. Banegas, J. Segura, L. M. Ruilope, M. Luque, R. Garciá-Robles, C. Campo, F. Rodriguez-Artalejo, and J. Tamargo, "Blood pressure control and physician management of hypertension in hospital hypertension units in Spain," Hypertension, vol. 43, no. 6, pp. 1338-1344, 2004. doi: https://doi.org/110.1161/ 01.HYP.0000127424.59774.84

[15] T. Kaewdok, S. Sirisawasd, and S. Taptagaporn, "Work posture assessment among elderly farmers in Pathumthani Province, Thailand," Journal of Advances in Health and Medical Sciences, vol. 4, no. 1, pp. 9-14, 2018. doi: https://doi.org/10.20474/ jahms-4.1.2

[16] M. G. Denker and D. L. Cohen, "What is an appropriate blood pressure goal for the elderly: Review of recent studies and practical recommendations," Clinical Interventions in Aging, vol. 8, p. 1505, 2013. doi: https://doi.org/10.2147/CIA.S33087

[17] R. Nahas, "Complementary and alternative medicine approaches to blood pressure reduction: an evidence-based review," Canadian Family Physician, vol. 54, no. 11, pp. 1529-1533, 2008.

[18] S. Chomcheoy, C. Teanchai, and A. Riddhabhaya, "Study of access to health services of the elderly in Tambon Ban Khetmuang district health promotion hospital, Tambon Lat Yai, Samut Songkhram province," Journal of Advances in Health and Medical Sciences, vol. 3, no. 3, pp. 117-125, 2017. doi: https://doi.org/10.20474/jahms-3.3.3

[19] M. Shahriari, M. Dehghan, S. Pahlavanzadeh, and A. Hazini, "Effects of progressive muscle relaxation, guided imagery and deep diaphragmatic breathing on quality of life in elderly with breast or prostate cancer," Journal of Education and Health Promo- 
tion, vol. 6, 2017. doi: https://doi.org/10.4103/jehp. jehp_147_14

[20] K. L. Kwekkeboom, C. H. Cherwin, J. W. Lee, and B. Wanta, "Mind-body treatments for the painfatigue-sleep disturbance symptom cluster in persons with cancer," Journal of Pain and Symptom Management, vol. 39, no. 1, pp. 126-138, 2010. doi: 10.1016/j.jpainsymman.2009.05.022

[21] A. Fattah, "The effect of holy quran voice on the quality of life among the elderly during coronavirus outbreak," International Journal of Psychosocial Rehabilitation, vol. 24, no. 08, p. 4984-4993, 2020. doi: https://doi.org/10.37200/IJPR/V24I8/ PR280513

[22] O. C. Salim, N. Sudharma, R. Kusumaratna, and A. Hidayat, "Validity and reliability of World Health Organization quality of life-BREF to assess the quality of life in the elderly," Universa Medicina, vol. 26, pp. 27-38, 2007.

[23] L. Resmiya and I. H. Misbach, "Development of Indonesian quality of life measurement tool," Journal Psikologi Insight, vol. 3, no. 1, pp. 20-31, 2020.

[24] N. N. Muhammad, H. Shatri, Z. Djoerban, and M. Abdullah, "Test the validity and reliability of the World Health Organization Quality of Life-HIV Bref questionnaire in Indonesian to measure the quality of life of HIV/AIDS patients," Journal of Internal Medicine in Indonesia, vol. 4, no. 3, pp. 112-122, 2017. doi: https://doi.org/10.7454/jpdi. v4i3.137

[25] A. Hassanpour-Dehkordi and A. Jalali, "Effect of progressive muscle relaxation on the fatigue and quality of life among Iranian aging persons," Acta Medica Iranica, pp. 430-436, 2016.

[26] P. M. Boyce, N. J. Talley, B. Balaam, N. A. Koloski, and G. Truman, "A randomized controlled trial of cognitive behavior therapy, relaxation training, and routine clinical care for the irritable bowel syndrome," The American Journal of Gastroenterology, vol. 98, no. 10, pp. 2209-2218, 2003. doi: https://doi.org/10.1111/j.1572-0241.2003.07716.x

[27] M.-R. Isa, F. M. Moy, A.-H. A. Razack, Z. M. Zainuddin, and N.-Z. Zainal, "Impact of applied progressive deep muscle relaxation training on the health related quality of life among prostate cancer patients-a quasi experimental trial," Preventive Medicine, vol. 57, pp. S37-S40, 2013. doi: https://doi.org/10.1016/j.ypmed.2013.02.011
[28] S. Ghafari, F. Ahmadi, M. Nabavi, K. Anoshirvan, R. Memarian, and M. Rafatbakhsh, "Effectiveness of applying progressive muscle relaxation technique on quality of life of patients with multiple sclerosis," Journal of Clinical Nursing, vol. 18, no. 15, pp. 2171-2179, 2009. doi: https://doi.org/10.1111/j. 1365-2702.2009.02787.x

[29] S. P. Prakash Jha and U. J. Deaver, "Effectiveness of Dance and Movement Therapy (DMT) and Progressive Muscle Relaxation (PMR) on Depression and Quality of Life (QOL) among elderly: A systematic review," International Journal of Health Sciences \& Research, vol. 8, no. 9, pp. 263-267, 2018.

[30] D. A. Bernstein, T. D. Borkovec, and H. HazlettStevens, New directions in progressive relaxation training: A guidebook for helping professionals. Westport, CT: Greenwood Publishing Group, 2000.

[31] A. Molassiotis, H. P. Yung, B. M. Yam, F. Y. Chan, and T. Mok, "The effectiveness of progressive muscle relaxation training in managing chemotherapy-induced nausea and vomiting in Chinese breast cancer patients: A randomised controlled trial," Supportive Care in Cancer, vol. 10, no. 3, pp. 237-246, 2002. doi: https://doi.org/10. 1007/s00520-001-0329-9

[32] I. Sulistyarini, "Relaxation therapy to lower blood pressure and improve the quality of life of people with hypertension," Journal of Psychology, vol. 40, no. 1, pp. 28-38, 2013.

[33] M. Mahjoob, J. Nejati, A. Hosseini, and N. M. Bakhshani, "The effect of Holy Quran voice on mental health," Journal of Religion and Health, vol. 55, no. 1, pp. 38-42, 2016. doi: https://doi.org/10.1007/ s10943-014-9821-7

[34] H. Sadeghi et al., "Voice of Quran and health: A review of performed studies in Iran," Quran and Medicine, vol. 1, no. 1, pp. 33-37, 2011.

[35] M.-Y. Chang, C.-H. Chen, and K.-F. Huang, "Effects of music therapy on psychological health of women during pregnancy," Journal of Clinical Nursing, vol. 17, no. 19, pp. 2580-2587, 2008. doi: https://doi.org/10.1111/j.1365-2702.2007.02064.x

[36] M. Kazemi, A. Ansari, M. Allah Tavakoli, and S. Karimi, "Impact on mental health nursing students reciting the Quran," Journal of Rafsanjan University of Medical Sciences, vol. 3, no. 1, pp. 52-7, 2003. 